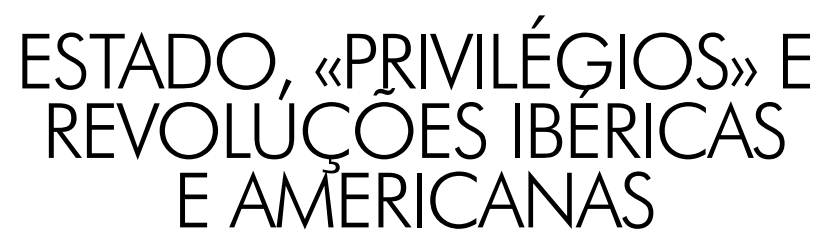

(D) Nuno Gonçalo Monteiro ${ }^{I ; 2}$

$\mathrm{N}$ os tempos que passam, ao menos quando estas linhas são escritas, a pandemia global convoca de uma forma inusitada a explicitação dos poderes, que se tornam mais visíveis por força das circunstâncias. Muitos exprimem as suas preocupações com o alargamento das atribuições do Estado nas condições do «estado de emergência», ao mesmo tempo que, nos grandes como nos pequenos países, se apreende a pluralidade, por vezes contraposta, dos polos de diversa escala geográfica que o conformam. De algum modo, regressa-se a questões com uma mais antiga genealogia intelectual, mas que sem dúvida tiveram um ciclo definidor no tempo dilatado das revoluções atlânticas e ibero-americanas, estas últimas todas estreitamente conectadas entre si.

1 Universidade de Lisboa. Lisboa - Portugal.

2 Investigador coordenador do Instituto de Ciência Sociais e professor catedrático convidado da Faculdade de Letras da Universidade de Lisboa. Publicou mais de duas centenas de títulos, incluindo a co-coordenação de Um reino e as suas repúblicas no Atlântico: comunicações políticas entre Portugal, Brasil e Angola nos séculos XVII e XVIII. (Civilização Brasileira, 2017) e de História Social Contemporânea: Portugal (1808-2000) (Objectiva, 2020). 
Claro que nesse período, de A. Smith e G.W. F. Hegel às múltiplas conceitualizações ibéricas e ibero-americanas, se reformularam ideias mais antigas. E também é indiscutível que o legado francês recente, com ênfase na votação da noite de 4 de agosto de 1789, para sempre associada ao que se designou de destruição do «regime feudal», pesou muito nas experiências ibéricas, tal como foi em numerosos casos formalmente reconhecido. No entanto, é também indubitável que nesses contextos existiram, não apenas incorporações de heranças anteriores associáveis a configurações territoriais, como o tópico da separação entre o público e o privado, entre autoridade e propriedade, entre Estado e sociedade civil. Mesmo quando ao Estado se não chamava «Estado», e até se dizia que era a organização política da «sociedade civil». De resto, a antiga polissemia da palavra iria arrastar-se muito para além do período aqui comentado, até à segunda metade do oitocentos.

Nos cenários espanhol e português, a questão da «feudalidade», para retomar um vocábulo francófono que hoje se encontra em desuso e que naqueles cenários também se podia chamar dos «senhorios» ou ser invocada através de outras designações («forais e bens da coroa»), ocupou um lugar intelectual, simbólico e político incontornável na produção da distinção entre público e privado. Embora com critérios variáveis, pretendeu-se em todos esses casos separar a renda do imposto, os proventos decorrentes da propriedade dos associados ao exercício da autoridade («senhorio jurisdicional»), as relações contratuais das imposições unilaterais. Acontece que no caso francês a nova «feudalidade» incluía um amplo conjunto de matérias, algumas pós medievais, que abrangiam não apenas a extinção dos direitos «feudais», mas a abolição dos dízimos, dos benefícios eclesiásticos, dos privilégios corporativos e também da venalidade dos ofícios. A questão das «feudalidades» ibéricas, por seu turno, foi amplamente debatida na historiografia sobre os primeiros liberalismos ibéricos produzida no período das transições democráticas, ou seja, nos anos 70 e 80 do século XX.

Não cabe duvidar que tais questões foram relevantes nas revoluções liberais ibéricas do primeiro terço do século XIX. Eram 
matérias emblemáticas e exemplares. Permitiam estabelecer uma fronteira entre um antes e um depois, conquistar apoios para a causa e consagrar a propriedade como fundamento da cidadania (os direitos senhoriais eram vistos como impostos recebidos por privados). $\mathrm{O}$ paradigma da monopolização dos poderes públicos, com a inerente concentração dos mecanismos de disciplinamento social, correspondia, na mesma escala, à delimitação inequívoca da esfera do particular. Construir a propriedade, plena e absoluta, implicava afrontar formas repartidas da mesma, libertá-la do que doravante se reputava tributações ilegítimas que sobre ela impendiam, em benefício das «classes privilegiadas», como se dizia por vezes. De resto, tal como os historiadores sociais um século e meio mais tarde se esforçaram por elucidar, as diversas soluções, a forma como se estabelecia a distinção entre imposto e renda, traduziam-se em incidências diversas sobre os múltiplos e opostos actores sociais. Em resumo, como declararia o deputado Manuel Gonçalves de Miranda nas Cortes de Lisboa em 1821: "Quais são os bens que tem a França? Qual é a prosperidade de que goza? Pois toda essa prosperidade a deve à tormentosa discussão de 4 de Agosto (de 1789), em que se aboliram os direitos, os privilégios, e tudo o que oprimia aquela nação». De facto, de acordo como que explicou pela mesma altura o deputado Bento Pereira do Carmo, «os privilégios (...) não estão em armonia com a igualdade civil, que forma a base do sistema representativo, aonde a lei deve ser igual para todos». E, como também afirmava no mesmo ano numa petição a câmara do minúsculo couto de Évora de Alcobaça, muito ativa nos conflitos com o mosteiro donatário, estava-se «numa época em que o direito de propriedade se acha solenemente sancionado nas bases (...) da nossa Constituição».

Embora a equivalente produção legislativa espanhola seja mais precoce, podendo sugerir-se que se prolonga entre 1811 e 1837, a legislação portuguesa da guerra civil (1832-34), em particular a associável à figura tão exaltada pela posteridade de J. X. Mouzinho da Silveira, merece uma referência peculiar pela sua dimensão invulgarmente sistemática, tendo sido decretada no ano de $1832 \mathrm{em}$ poucos meses, entre a Ilha Terceira nos Açores e a cidade do Porto, pela regência 
liberal em guerra com os miguelistas. Como se pode constatar pelos preâmbulos dos decretos e em outros escritos do autor, combinou a abolição de direitos senhoriais e dízimos e a extinção parcial dos morgados, com a reforma administrativa que suprimiu o poder judicial das câmaras e estabeleceu um modelo centralista de governo local, cruzando uma inspiração smithiana com os modelos franceses da revolução e do império, que se associavam a uma apologia do governo forte. Os seus pressupostos foram explicitados em textos anteriores: «o liberalismo dos antigos não provinha da força da opinião dos povos, nem dos seus conhecimentos; ele consistia antes no espírito do privilégio, e na força do carácter indomável das grandes classes»; entretanto «os governos desfizeram-se dessas forças a pouco, e pouco, e nas sociedades modernas nenhuma corporação é mais poderosa do que o governo; o qual tendo desfeito, ou submetido a todas aparece mais poderoso, e influente, que nunca»; por isso, «o liberalismo moderno é cousa muito diferente; ele não consiste nos privilégios das cidades, nem no espírito das corporações mas é resultado da análise aplicada às deliberações do governo, e do desejo natural de melhorar a sua condição».

Os fundamentos da sua utopia legislativa eram claros. A definitiva separação do Brasil modificava as coisas sem possibilidades de retorno. Como escreverá no preâmbulo ao decreto da abolição dos dízimos eclesiásticos de 30-VI-1832 : «o Reino, tendo feito grandes Conquistas, viveu por mais de três séculos do trabalho dos escravos, e que perdidos os escravos, era preciso criar uma nova maneira de existência, multiplicando os valores pelo trabalho próprio [...] vi na separação do Brasil um acontecimento ainda mais fértil em consequências, do que foi a descoberta». Desde logo porque impunha «mudanças radicais» em matérias financeiras pois, tal como escrevera antes, «os eclesiásticos recebem os dízimos que partilham com os aristocratas (...) e isso ultrapassa em muito os rendimentos do Estado» (1829). Falava, de resto, na «mais vil e sórdida aristocracia que a história nos tem feito conhecer» e visava atacar «a gente privilegiada que vivia do suor alheio, (e) estimava que os Reis dispusessem dos bens do Povo, porque de facto dispunham desses bens a favor deles», sabendo que 
era necessário «aproveitar os conhecimentos da Europa civilizada, e arrancar das mãos dos inimigos o fruto dos trabalhos dos Povos». No decreto de 13-VIII-1832 de abolição dos forais e dos bens da coroa, reputado muitas vezes a lei das leis, a clara separação público e privado não consente que os privados recebam tributos, categoria a que são remetidos os dízimos (já abolidos) e os direitos senhoriais: (Art. 4) «As Contribuições, e Tributos pagos pelos Povos, sendo essencialmente destinados para as despesas públicas, não podem fazer o Património de alguma Corporação, ou indivíduo de qualquer hierarquia que seja: as Contribuições, e Tributos serão de sua natureza gerais, e devem ser repartidas entre todos os habitantes da Monarquia, segundo as Leis gerais». Por isso mesmo se esclarece que «as disposições do presente Decreto em nada alteram a Legislação dos contratos feitos sobre Bens Patrimoniais dos Particulares». Já em maio de 1832 os decretos sobre a administração pública portuguesa, anunciavam no preâmbulo que «a mais bela, e útil descoberta moral do Século passado foi, sem dúvida, a diferença entre administrar e julgar». Determinar-se-á, assim, não apenas a reorganização da fazenda pública mas a total separação entre poder judicial e poder administrativo, a todos os níveis da administração pública. No que se refere às câmaras municipais tal irá significar que perderão para sempre o poder judicial em primeira instância que detinham desde a Idade Média até então, competência transferida para os juízes letrados dos tribunais de comarca, então criados e, em matéria administrativa, que passarão a ser tuteladas por um provedor de nomeação governamental, parte de uma cadeia hierárquica que culminava no ministro do reino. Muito contestada desde o início, esta dimensão da reforma, de clara inspiração napoleónica (mas também com antecedentes no Brasil) e geralmente reputada de cunho muito centralizador, deixará uma marca durável na administração portuguesa. De resto, a legislação posterior, decretada já depois da saída de Mouzinho do governo, abrangerá, até 1834/35, quase todos os domínios: extinção das ordens religiosas regulares e nacionalização dos seus bens posteriormente vendidos; supressão de todos os tribunais superiores; abolição das corporações de ofícios mecânicos; abolição das milícias e ordenanças; supressão dos cadetes no exército; extinção da maior parte das 
câmaras municipais. Tudo isso teria uma concretização variável, tal como o código civil teria ainda de esperar até 1867 e o alargamento efetivo da esfera da intervenção dos poderes públicos em áreas com a educação ou a saúde mais tempo ainda. Seria matéria do futuro.

Os processos de implantação do liberalismo precocemente triunfante na Península ibérica em cenários de confronto político e militar estiveram associados, ao menos na letra dos seus decretos, à consagração de mudanças relevantes na ordem civil. Mais exatamente, a produção normativa do «Estado» foi indissociável da produção da sociedade e dos seus cidadãos activos. O programa liberal não podia separar o «sistema representativo» e as reformas «civis». Desde os primórdios da presença francesa que se pediram réplicas do código civil napoleónico. A hegemónica prevalência nas últimas décadas de leituras estritamente políticas das revoluções liberais tende a fazer esquecer essas dimensões essenciais, de resto, parte incontornável das disputas políticas. O resultado dos grandes debates historiográficos dos anos de 1970 e 1980 sobre a Revolução Francesa foi durante as subsequentes décadas o inexorável declínio da história (também) social da mudança política. Certamente por caminhos novos, talvez seja a hora de rever a revisão.

Será que tudo o que se disse pode, de algum modo, ser transposto para os «tempos de revolução» das independências ibero-americanas? O assunto já foi mil vezes debatido. Também se discutiu, e se questionou, a existência ou não de cenários «civis» similares nos vários territórios americanos, em particular entre o Brasil e as díspares Américas hispânicas. Não estão em questão as interdependências políticas e intelectuais, entre a Europa e as Américas, mas a coincidência das agendas. Múltiplos são os parâmetros que se podem considerar. Retomar um tópico que Tocqueville desenvolvia para outras latitudes, invocando John Armitage, que considerava em 1836 que «a nobreza no Brasil não era, como na Europa, uma instituição que nascera espontaneamente do sistema feudal» e que no Brasil não existiam «ordens privilegiadas investidas de interesses opostos aos da sociedade». Ou sugerir que a questão da terra, associada sobretudo ao tópico da sua demarcação, se equacionava em termos diversos dos cenários 
europeus (não havia um antes e um depois tão afirmados), naqueles se incluindo a espoliação de populações ameríndias. Em particular, pode sempre realçar-se que a terra nunca prevaleceu sobre o problema do acesso à mão de obra. E, com isto, chegamos à incontornável questão da escravidão, em larga medida silenciada no processo da independência, e dos dois lados do Atlântico. Matéria sobre a qual os liberalismos políticos, em Portugal e no Brasil, tiveram sempre uma posição ambivalente e pouco explícita, não obstante a intransigência abolicionista de alguns. Por fim, pode sempre argumentar-se que as questões territoriais tiveram um papel fundamental nas independências americanas, prevalecendo frequentemente sobre outras. Mesmo quando acabaram por se preservar, no essencial, os limites das mais antigas circunscrições.

Enfim, esta pequena digressão pretendeu apenas retomar um tópico antigo, talvez demasiado obliterado nas historiografias recentes. Glosas marginais e talvez euro-centradas. Mas não, certamente, cronocentricas. É por isso que se deve sugerir que as lógicas corporativas coexistiram com o imaginário oitocentista do público e do privado aqui descrito.

\section{Bibliografia sumária}

ARMITAGE, Joao. Historia do Brasil: desde o periodo da chegada da familia de Braganca, em 1808, ate a abdicacao de d. Pedro I, em 1831, compilada a vista dos documentos públicos e outras fontes originais formando uma continuacao da Historia do Brasil, de Southey. Belo Horizonte: Itatiaia/Sao Paulo: EDUSP, 1981

BLAUFARB, Rafe, L'invention de la propriete privee. Une autre histoire de la revolution, , Champ Vallon, 2019

HESPANHA, Antonio Manuel, "La revolucion y los mecanismos del poder (18201851)",in Carlos Petit (coord.), Derecho privado y revolucion burguesa, Madri, Marcial Pons, 1990

LEMPERIERE, Annick (editora), Estado, tomo 3/10 de Javier Fernandez Sebastian (Dir.), Diccionario Politico y social del mundo iberoamericano. 
Conceptos politicos fundamentales, 1770-1870 Universidad del Pais Vasco/ Centro de Estudios Politicos y Constitucionales, Madrid, 2014.

MONTEIRO, Nuno Goncalo, «Regime senhorial e revolucao liberal», II Parte de Elites e Poder. Entre o Antigo Regime e o Liberalismo, $3^{\mathrm{a}}$ ed., Lisboa, Imprensa das Ciencias Sociais, 2012.

Recebido em: 01/04/2020 - Aprovado em: 20/04/2020 